\title{
Refraction correction for radio-echo sounding of large ice masses
}

\author{
W. G. REES \\ Scott Polar Research Institute, University of Cambridge, Cambridge CB2 1ER, England \\ R. E. Donovan \\ Christ's College, Cambridge CB2 3BU, England
}

\begin{abstract}
This paper presents a simple mathematical formula for correcting radio-echo-sounding data from an ice sheet or glacier for the effects of varying refractive index. The method requires some knowledge of the variation of refractive index with depth. In rare cases this may be known from direct measurement, but it can be estimated from the density profile. If even this is unknown, we show that the corrections can be estimated to an accuracy of about $3 \%$ of the depth to bubble closeoff (i.e. to about $\pm 2 \mathrm{~m}$ for dry-snow conditions), and that the size of the refraction correction for a glacier or ice sheet with a flat bed is typically $6-10 \mathrm{~m}$ under these conditions.
\end{abstract}

\section{INTRODUCTION}

At VHF frequencies $(\approx 100 \mathrm{MHz})$, ice is one of the most transparent of geophysical materials, and pulses of radiofrequency energy can propagate through it without significant loss for hundreds of metres. This fact has been used extensively in the technique of radio-echo sounding to determine the thickness of some of the world's large ice sheets (see Macqueen, 1988; and references therein). However, the refractive index of an ice sheet is not constant, increasing with depth, and this introduces problems to accurate radio-echo sounding. Expressed in its simplest form, the problem is that a ray travels vertically downwards, is reflected from bedrock, and returns, will take less time to do so than it would if the refractive index were constant at the value appropriate to deep ice. The thickness of the ice mass will thus be underestimated and must be corrected appropriately, by typically $10 \mathrm{~m}$, for accurate determinations of thickness. However, a more complicated problem arises if the underlying bedrock is inclined with respect to the horizontal (and indeed this situation is glaciologically more interesting since the slope of the bedrock is an important source of driving stress on an ice mass). In this case, the ray which reaches the bedrock in the shortest time does not propagate vertically and indeed does not describe a straight line. This causes particular difficulty in determining the point on the bedrock surface at which a ray is reflected and hence in deducing the profile of the bedrock surface.

This problem has been addressed by Rasmussen (1986), who used a variety of models of $n(z)$ (the variation of refractive index with depth) for which he derived analytic solutions of the ray equations. The resulting correction formulae can be unwieldy in practice, and there exists the possibility that the refractive-index profile of a real ice mass may not be adequately described by the models. In the present paper, we derive a more general approach to the problem, in which no model of $n(z)$ is assumed and corrections to the apparent bedrock position are expressed as polynomial expansions in the bedrock-slope angle. The coefficients of the polynomials are obtained from integrals of $n(z)$, which can be derived directly if $n(z)$ is known, and indirectly but sufficiently accurately if the density profile $\rho(z)$ is known. We analyse a number of density profiles to determine typical values of the coefficients for dry-snow ice masses, so that even if no data are available about the variation of $n$ or $\rho$ with depth, a reasonably accurate correction can be calculated.

\section{ANALYSIS}

We assume that the refractive index $n$ of the ice varies only with depth $z$ (and is therefore independent of horizontal position, i.e. the ice is stratified), until it reaches a constant value $n_{\mathrm{i}}$ (the refractive index of pure ice) at a depth $z_{\mathrm{f}}$. We also assume that the bedrock surface, from which the radio signals are reflected, lies deeper than this value $z_{\mathrm{f}}$. In order to simplify the analysis but, without significant loss of generality, we will also assume that the bedrock surface is planar, with a slope parallel to the direction in which the radio-echo-sounding traverse is made (which we will define to be the $x$ direction). Rays will thus be confined to the $x-z$ plane (see Fig. 1).

A bundle of rays, with a wide spread in angle, is 


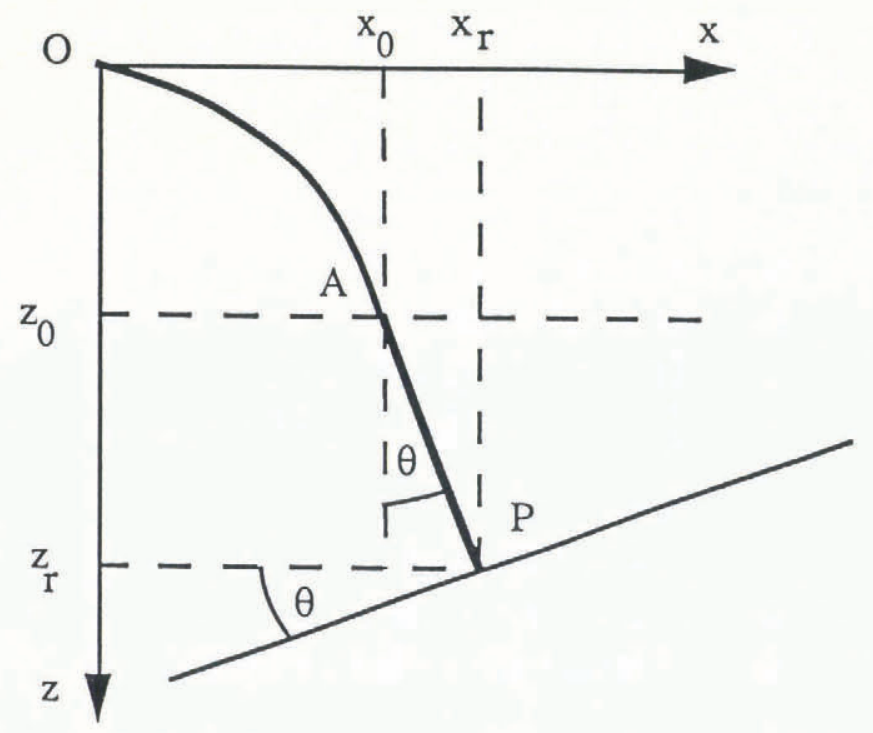

Fig. 1. A ray follows a curvilinear path from the surface $(z=0)$ to the point $A$, beyond which the refractive index of the ice becomes constant. The ray then describes a straight line until it strikes the bedrock perpendicularly at the point $P$.

emitted at the origin $\mathrm{O}$ of the coordinate system and at time zero, and propagates into the ice. It will be proved below that the ray which reaches the bedrock surface (which is inclined at an angle $\theta$ to the horizontal) in the shortest time is the ray which makes an angle $\theta$ to the vertical when it is within the region of constant refractive index $\left(z>z_{\mathrm{f}}\right)$. This ray follows a curvilinear path when $z<z_{\mathrm{f}}$, reaching the point $\mathrm{A}\left(x_{\mathrm{f}}, z_{\mathrm{f}}\right)$ at time $t_{\mathrm{f}}$, after which it follows a straight path until it reaches the bedrock at the point $\mathrm{P}\left(x_{\mathrm{r}}, z_{\mathrm{r}}\right)$ at time $T$. The ray is reflected at this point, and exactly retraces its path until it reaches $\mathrm{O}$ at time $2 T$. The problem we have to solve is to determine the coordinates $\left(x_{\mathrm{r}}, z_{\mathrm{r}}\right)$ of the point $\mathrm{P}$ in terms of the two measurable parameters $T$ (the one-way travel time) and $\theta$ (the bedrock slope). We will show below that $\theta$ can be determined from the radio-echo sounding measurements.

Following Rasmussen (1986), we may put

$$
x_{\mathrm{f}}=n_{\mathrm{i}} \sin \theta \int_{0}^{z_{\mathrm{f}}} \frac{\mathrm{d} z}{\sqrt{n^{2}-n_{\mathrm{i}}^{2} \sin ^{2} \theta}}
$$

and

$$
t_{\mathrm{f}}=\frac{1}{c} \int_{0}^{z_{\mathrm{f}}} \frac{n^{2} \mathrm{~d} z}{\sqrt{n^{2}-n_{\mathrm{i}}^{2} \sin ^{2} \theta}}
$$

for the coordinates of the point A. Beyond $\mathrm{A}$ the ray travels in a straight line for a time $\left(T-t_{\mathrm{f}}\right)$, and hence a distance $c\left(T-t_{\mathrm{f}}\right) / n_{\mathrm{i}}$, until it reaches the bedrock at $\mathrm{P}$. The coordinates of $\mathrm{P}$ are thus given by

$$
x_{\mathrm{r}}=x_{\mathrm{f}}+\frac{c\left(T-t_{\mathrm{f}}\right) \sin \theta}{n_{\mathrm{i}}}
$$

$$
\text { and }
$$

$$
z_{\mathrm{r}}=z_{\mathrm{f}}+\frac{c\left(T-t_{\mathrm{f}}\right) \cos \theta}{n_{\mathrm{i}}} .
$$

Substituting from Equations (1) and (2), we obtain the desired results:

$$
\begin{gathered}
x_{\mathrm{r}}=\frac{c T \sin \theta}{n_{\mathrm{i}}}+n_{\mathrm{i}} \sin \theta \int_{0}^{z_{\mathrm{f}}} \frac{\mathrm{d} z}{\sqrt{n^{2}-n_{\mathrm{i}}^{2} \sin ^{2} \theta}} \\
\quad-\frac{\sin \theta}{n_{\mathrm{i}}} \int_{0}^{z_{\mathrm{f}}} \frac{n^{2} \mathrm{~d} z}{\sqrt{n^{2}-n_{\mathrm{i}}^{2} \sin ^{2} \theta}} \\
z_{\mathrm{r}}=\frac{c T \cos \theta}{n_{\mathrm{i}}}+z_{\mathrm{f}}-\frac{\cos \theta}{n_{\mathrm{i}}} \int_{0}^{z_{\mathrm{f}}} \frac{n^{2} \mathrm{~d} z}{\sqrt{n^{2}-n_{\mathrm{i}}^{2} \sin ^{2} \theta}} .
\end{gathered}
$$

In these two expressions, the first terms are the usual result (i.e. corrected for slope but uncorrected for refraction) and the following terms represent the refraction corrections.

We can use Equations (3) and (4) to show that the ray which reaches the bedrock in the shortest time must strike it perpendicularly (i.e. that the ray must make an angle of $\theta$ to the vertical in the region where the refractive index is constant, if the bedrock makes an angle of $\theta$ to the horizontal). The shortest time is significant because this is what is determined by the radio-echo-sounding technique.

Partial differentiation of Equation (3) with respect to $\theta$ at constant $T$ gives

$\frac{\partial x_{\mathrm{r}}}{\partial \theta}=\frac{c T \cos \theta}{n_{\mathrm{i}}}+n_{\mathrm{i}} \cos \theta \int_{0}^{z_{\mathrm{f}}} \frac{n^{2}\left(1-n^{2} / n_{\mathrm{i}}^{2}\right) \mathrm{d} z}{\left(n^{2}-n_{\mathrm{i}}^{2} \sin ^{2} \theta\right)^{3 / 2}}$

and similarly differentiation of Equation (4) gives

$$
\frac{\partial z_{\mathrm{r}}}{\partial \theta}=-\frac{c T \sin \theta}{n_{\mathrm{i}}}-n_{\mathrm{i}} \sin \theta \int_{0}^{z_{\mathrm{f}}} \frac{n^{2}\left(1-n^{2} / n_{\mathrm{i}}^{2}\right) \mathrm{d} z}{\left(n^{2}-n_{\mathrm{i}}^{2} \sin ^{2} \theta\right)^{3 / 2}} .
$$

Combining Equations (5) and (6) shows that $\partial x_{\mathrm{r}} / \partial z_{\mathrm{r}}$ at constant $T$ is $-\cot \theta$ and, since $\partial x / \partial z$ for the ray, as we have defined it, is $+\tan \theta$, it follows that a surface of constant travel time is perpendicular to the ray. From this it also follows that the ray which reaches the bedrock in the shortest time must strike it perpendicularly.

This result may in turn be used to show how the bedrock slope can be determined from surface obser-

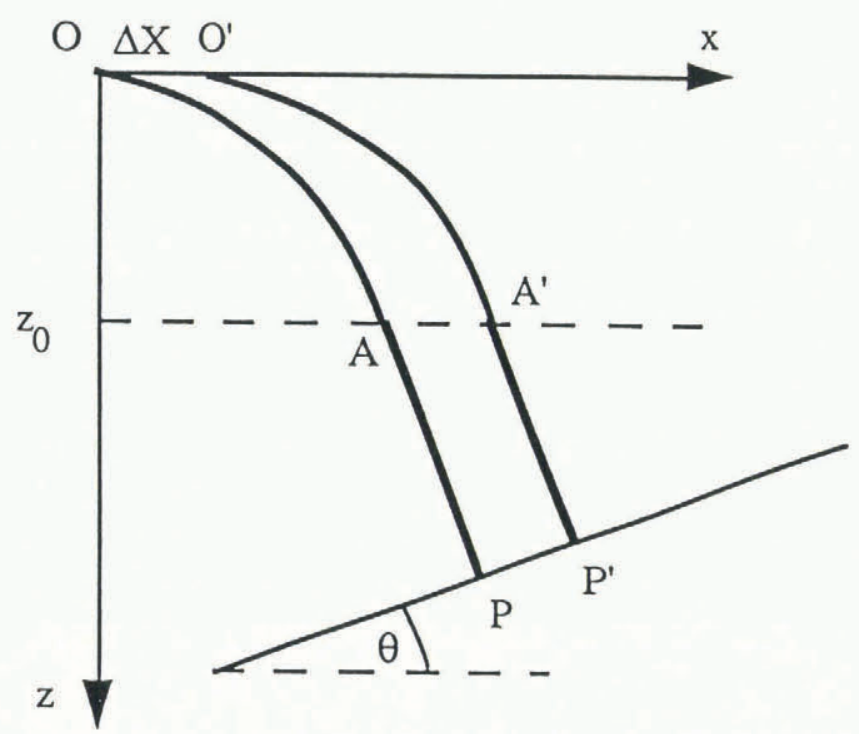

Fig. 2. Determining the bedrock-slope angle $\theta$ from surface observations (see text for details). 
vations. Suppose that the shortest travel time to the bedrock is determined from the point $\mathrm{O}$, and also from the point $\mathrm{O}^{\prime}$ which has $x$-coordinate $\Delta X$ (see Fig. 2).

It is clear that the travel times from $\mathrm{O}$ to $\mathrm{A}$ and from $\mathrm{O}^{\prime}$ to $\mathrm{A}^{\prime}$ must be identical, so the only difference arises from the difference in the path lengths $\mathrm{AP}$ and $\mathrm{A}^{\prime} \mathrm{P}^{\prime}$. If the one-way travel time from $\mathrm{O}^{\prime}$ to $\mathrm{P}^{\prime}$ is less than that from $\mathrm{O}$ to $\mathrm{P}$ by $\Delta T$, it thus follows that

$$
\sin \theta=\frac{c}{n_{\mathrm{i}}} \frac{\Delta T}{\Delta X}
$$

(Harrison, 1970). The bedrock slope $\theta$ can thus be determined from the rate of change of travel time with surface position, as usual in the relocation of radio-echosounding data.

In principle, then, we now have enough information to determine the location $\left(x_{\mathrm{r}}, z_{\mathrm{r}}\right)$ of the point $\mathrm{P}$ at which a ray from $\mathrm{O}$ is reflected at the bedrock. The bedrock slope is obtained from Equation (7), and the coordinates of the reflection point are then given by Equations (3) and (4). However, these equations are not particularly simple to apply unless the refractive-index profile $n(z)$ can be approximated by a simple analytic expression (e.g. Rasmussen, 1986).

We adopt a more general approach by expanding the integrals of Equations (3) and (4) as polynomials in $\sin \theta$ and $\cos \theta$. Specifically, we may write

$$
\begin{aligned}
x_{\mathrm{r}}= & \frac{c T \sin \theta}{n_{\mathrm{i}}}+\sum_{m=0}^{\infty} \frac{(2 m) !}{2^{2 m}(m !)^{2}}\left(I_{-2 m-1}\right. \\
& \left.-I_{1-2 m}\right) \sin ^{2 m+1} \theta
\end{aligned}
$$

and

$$
z_{\mathrm{r}}=\frac{c T \cos \theta}{n_{\mathrm{i}}}+z_{\mathrm{f}}-\sum_{m=0}^{\infty} \frac{(2 m) !}{2^{2 m}(m !)^{2}} I_{1-2 m} \cos \theta \sin ^{2 m} \theta
$$

where the general integral $I_{p}$ is defined by

$$
I_{p}=\int_{0}^{z_{\mathrm{f}}}\left(n / n_{\mathrm{i}}\right)^{p} \mathrm{~d} z
$$

Thus, if $n(z)$ is known, the integrals $I_{p}$ can be evaluated for different values of $p$ and the correction terms obtained from Equations (8) and (9). For practical purposes, however, we may obtain expressions which are rather simpler to use by expanding $\cos \theta$ and $\sin \theta$ as polynomials in $\theta$, where $\theta$ is expressed in radians. In general, we may write

$$
x_{\mathrm{r}}=\frac{c T \sin \theta}{n_{\mathrm{i}}}+\xi_{0}+\xi_{1} \theta+\xi_{2} \theta^{2}+\xi_{3} \theta^{3}+\ldots
$$

and

$$
z_{\mathrm{r}}=\frac{c T \cos \theta}{n_{\mathrm{i}}}+\zeta_{0}+\zeta_{1} \theta+\zeta_{2} \theta^{2}+\zeta_{3} \theta^{3}+\ldots
$$

It can be shown that the $\xi_{i}$ are zero when $i$ is even, and that the $\zeta_{i}$ are zero when $i$ is odd. The first few non-zero terms are given in Table 1 in terms of the integrals $I_{p}$.
Table 1. The coefficients $\xi_{i}$ and $\zeta_{i}$ of Equations (11) and (12) evaluated in terms of the general integral $I_{p}$ of the refractive index defined by Equation (10)

$$
\begin{array}{ll}
\xi_{1} & I_{-1}-I_{1} \\
\xi_{3} & \frac{1}{2} I_{-3}-\frac{2}{3} I_{-1}+\frac{1}{6} I_{1} \\
\xi_{5} & \frac{3}{8} I_{-5}-\frac{5}{8} I_{-3}+\frac{31}{120} I_{-1}-\frac{1}{120} I_{1} \\
\xi_{7} & \frac{5}{16} I_{-7}-\frac{5}{8} I_{-5}+\frac{11}{30} I_{-3}-\frac{137}{2520} I_{-1}+\frac{1}{5040} I_{1} \\
\zeta_{0} & I_{0}-I_{1} \\
\zeta_{2} & -\frac{1}{2} I_{-1}+\frac{1}{2} I_{1}=-\frac{1}{2} \xi_{1} \\
\zeta_{4} & -\frac{3}{8} I_{-3}+\frac{5}{12} I_{-1}-\frac{1}{24} I_{1} \\
\zeta_{6} & -\frac{5}{16} I_{-5}+\frac{7}{16} I_{-3}-\frac{91}{720} I_{-1}+\frac{1}{720} I_{1}
\end{array}
$$

\section{ESTIMATION OF $\xi_{i}$ AND $\zeta_{i}$ FOR REAL ICE MASSES}

Equations (11) and (12) show how to correct a radioecho-sounding measurement for the effects of varying refractive index. Application of these equations requires knowledge of the coefficients $\xi_{i}$ and $\zeta_{i}$. Table 1 shows how they may be calculated from the refractive-index profile $n(z)$, using the definition of $I_{p}$ in Equation (10), but $n(z)$ is a parameter which is seldom measured for an ice sheet or a glacier. However, the refractive index $n$ is determined principally by the density $\rho$, and density profiles $\rho(z)$ are more often available. In this section we discuss the relationship between $\rho$ and $n$, and analyse a number of published $\rho(z)$ profiles to deduce the corresponding coefficients $\xi_{i}$ and $\zeta_{i}$.

The simplest physically plausible assumption for the relationship between the density and the refractive index is that of linearity:

$$
n=1+K \rho .
$$

The constant $K$ is clearly given by

$$
K=\left(n_{\mathrm{i}}-1\right) / \rho_{\mathrm{i}}
$$

where $n_{\mathrm{i}}$ and $\rho_{\mathrm{i}}$ are respectively the refractive index and the density of pure ice. Departures from this relationship are caused mainly by variations in the internal structure of the ice sheet, summarized by a structural parameter known as the Formzahl $u$. For a ray propagating vertically, a Formzahl $u=0$ corresponds to ice in vertical layers, $u=2$ to ice with no preferred direction and $u=\infty$ to horizontal layers of ice. Figure 3 (replotted from Evans (1965)) shows the expected variation of $n$ with $\rho$ for these three values of Formzahl, assuming $n_{\mathrm{i}}=1.77$ and $\rho_{\mathrm{i}}=920 \mathrm{~kg} \mathrm{~m}^{-3}$ (these numerical values are discussed below).

From Figure 3 it can be seen that, if $u$ takes any value between 2 and $\infty$, the linear assumption of Equation (13) is a reasonably accurate one. Evans (1965) stated that any value between 2 and $\infty$ must be expected in practice and, since we are unlikely to possess detailed knowledge of the variation of $u$ with depth, there seems little 


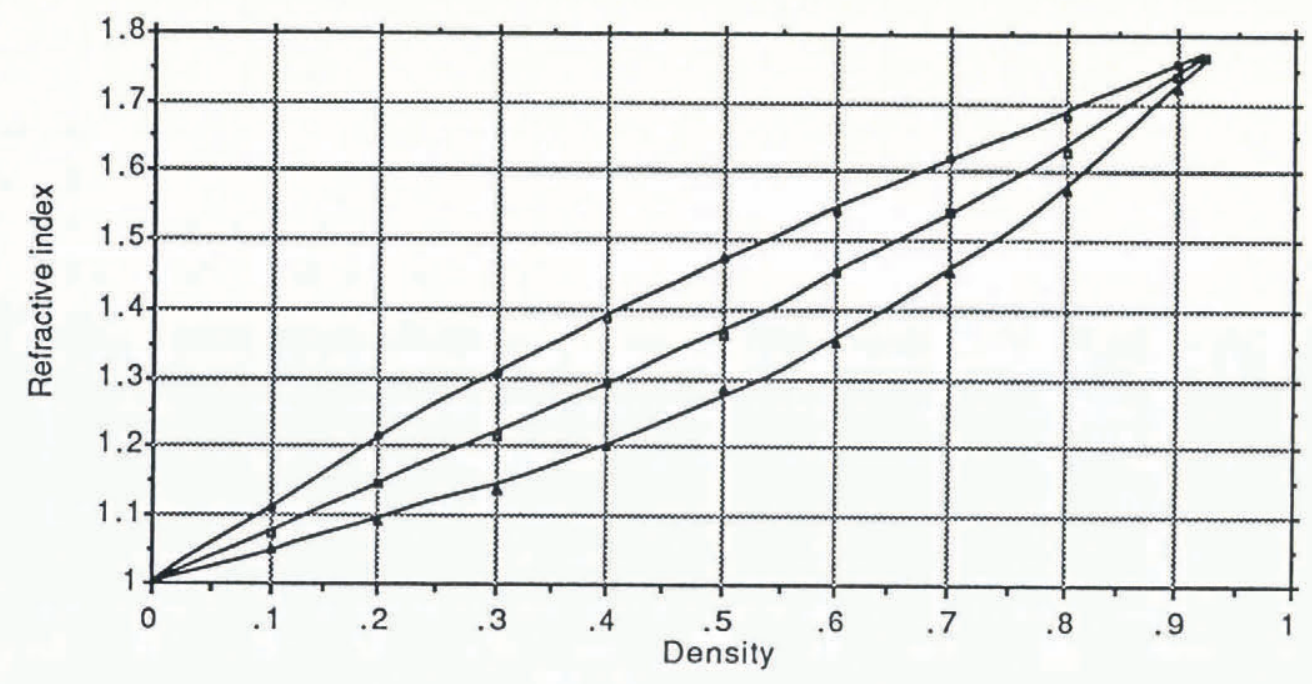

Fig. 3. Refractive index as a function of density of ice (in $\mathrm{Mg} \mathrm{m}^{-3}$ ) for different values of the Formzahl $u$. The upper curve corresponds to $u=\infty$, the middle curve to $u=2$ and the lower curve to $u=0$.

justification in adopting a model more complicated than that of Equation (13).

In order to apply Equation (13) to $\rho(z)$ profiles for real ice masses we must determine the constant $K$ from Equation (14). First we consider the density $\rho_{\mathrm{i}}$ of pure ice.

At the surface of an ice sheet or glacier, ice is deposited as snow crystals which, after it has settled, has a density of typically $200-300 \mathrm{~kg} \mathrm{~m}^{-3}$ or $350-400 \mathrm{~kg} \mathrm{~m}^{-3}$ if packed by wind (Seligman, 1936). At greater depths this material is compressed by the mass of the overlying material, increasing the density and resulting in a material which is normally (though erroneously; see Paterson, 1981) known as firn. At a depth sufficient for the density to have reached a value of about $830 \mathrm{~kg} \mathrm{~m}^{-3}$ (typically about $70 \mathrm{~m}$ if the firn is dry, and less if wet), the interconnecting air passages between the grains of ice are sealed off ("bubble close-off') and the material is more accurately described as glacier ice. This ice is less dense than pure ice because of the trapped air bubbles, and some further increase of density occurs with increasing depth. Temperature effects are also significant in modifying the density, and are discussed below.

Anderson and Benson (1963) quoted a density value for pure ice under laboratory conditions of $917 \mathrm{~kg} \mathrm{~m}^{-3}$, and Salamatin and others (1985) reported a value of $916.7 \mathrm{~kg} \mathrm{~m}^{-3}$ for deep glacier ice, although this of course was measured in the laboratory after the core had been retrieved. When this figure is corrected for the effects of pressure, the density of deep ice is found to be about $920 \mathrm{~kg} \mathrm{~m}^{-3}$. Nakawo (1986) quoted a value of $919.6 \pm 0.1 \mathrm{~kg} \mathrm{~m}^{-3}$ for deep $(400 \mathrm{~m})$ ice, which is consistent with Salamatin and others' measurement. Nakawo's figure can be corrected for the effects of air bubbles to derive the density of pure ice at a depth of $400 \mathrm{~m}$ by assuming that the entrapped air at $70 \mathrm{~m}$ depth (bubble close-off) has a volume of $10^{-4} \mathrm{~m}^{3} \mathrm{~kg}^{-1}$ of ice (Nakawo, 1986), and that below this it is in temperature and pressure equilibrium with the ice. At a depth of $400 \mathrm{~m}$ and a temperature of $-35^{\circ} \mathrm{C}$, the correction to the density is approximately $1.7 \mathrm{~kg} \mathrm{~m}^{-3}$, giving a density for pure ice under these conditions of $921.8 \pm 0.5 \mathrm{~kg} \mathrm{~m}^{-3}$. However, Nakawo suggested that his density estimate was too high by approximately $0.5 \mathrm{~kg} \mathrm{~m}^{-3}$, giving a final figure of $921.3 \pm 0.5 \mathrm{~kg} \mathrm{~m}^{-3}$.

This figure can be compared with the laboratory value by correcting for the compressibility and volumetric thermal expansivity of ice. The effect of an overburden of $400 \mathrm{~m}$ of ice is to increase the density by approximately $0.25 \mathrm{~kg} \mathrm{~m}^{-3}$, assuming a bulk elastic modulus of $13 \mathrm{GPa}$, and the effect of a temperature of $-35^{\circ} \mathrm{C}$ is to increase the density by approximately $4.9 \mathrm{~kg} \mathrm{~m}^{-3}$, assuming a volumetric expansivity of $1.53 \times 10^{-4} \mathrm{~K}^{-1}$. Thus, Nakawo's data are consistent with a density for pure ice under laboratory conditions of $916.5 \pm 0.5 \mathrm{~kg} \mathrm{~m}^{-3}$, which we shall take as a standard.

The refractive index $n_{\mathrm{i}}$ of pure (polycrystalline) ice is less well determined than the density, and this will therefore contribute more to the uncertainty in $K$. Although Yoshino (1961) reported a weak frequencydependence in the VHF band, this is now generally discredited (see Evans, 1965; Fitzgerald and Paren, 1975; Robin, 1975; Bogorodsky and others, 1985). More significant is a small temperature effect, which decreases the value of $n_{\mathrm{i}}$ by about 0.02 between $-1^{\circ} \mathrm{C}$ and $-60^{\circ} \mathrm{C}$ (Nakawo, 1986). Statistical combination of avalues of $n_{\mathrm{i}}$ for pure ice collected by Bogorodsky and others (1985), and values reported by Robin (1975) and Jezek (1985), gives a figure of $1.77 \pm 0.01$. Since the uncertainty in this result is comparable to the difference produced by large differences in temperature, it is reasonable to accept this value as appropriate to polycrystalline ice at a density of $916.5 \mathrm{~kg} \mathrm{~m}^{-3}$ and normal glacier temperatures. It is consistent with a more accurate but unpublished measurement at Dye-3 due to Gorman (personal communication). Finally, then, we can evaluate the constant $K$ from Equation (14) as $(0.77 \pm 0.01) /$ $(916.5 \pm 0.5) \mathrm{m}^{3} \mathrm{~kg}^{-1}$. Thus,

$$
K=(8.4 \pm 0.1) \times 10^{-4} \mathrm{~m}^{3} \mathrm{~kg}^{-1}
$$

\section{at $100 \mathrm{MHz}$.}

This value of $K$ has been used to derive profiles of $n(z)$ for profiles of $\rho(z)$ published by a number of workers. In order to obtain a reasonably uniform data set, we have 


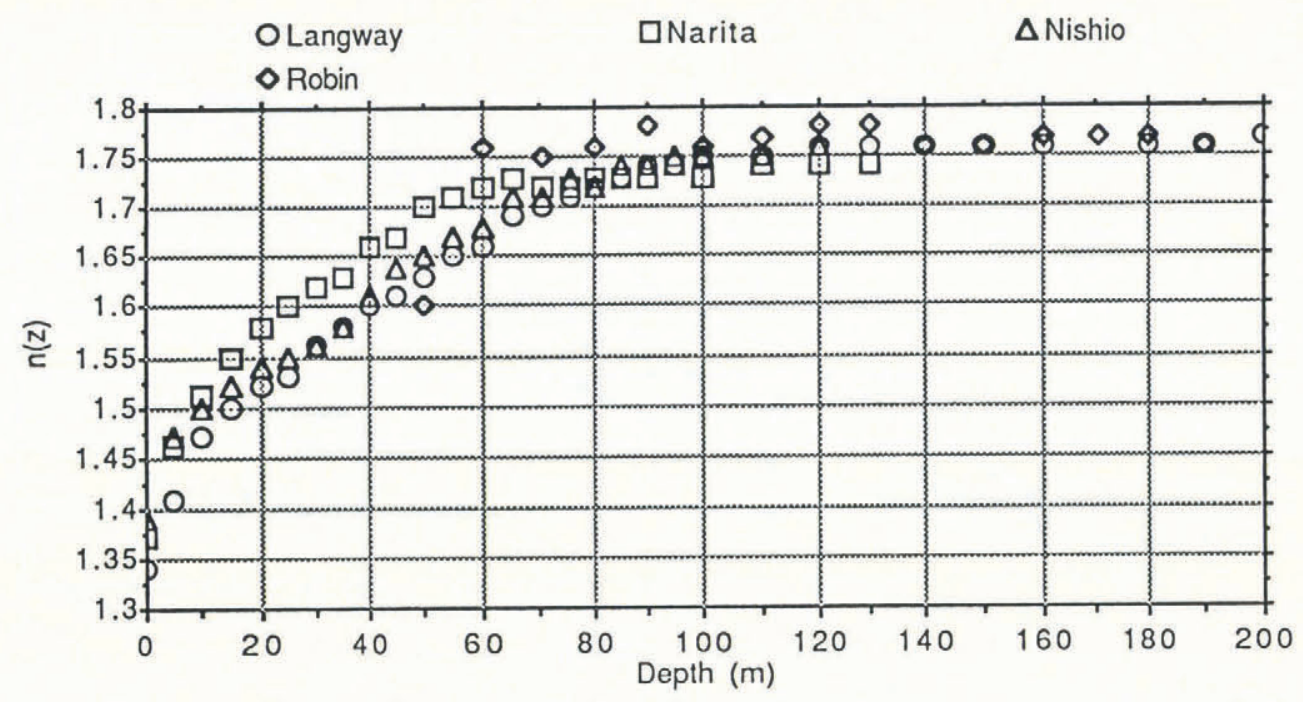

Fig. 4. VHF refractive index plotted against depth for the data sets discussed in the text.

restricted our analysis to dry-firn ice masses, i.e. those for which the depth of bubble close-off is about $70 \mathrm{~m}$, and have excluded measurements from blue-ice areas. The data sets we have used are from Site 2, Greenland (Langway, 1967), Mizuho, Antarctica (Narita and Maeno, 1978), and from G2, Antarctica (Nishio, 1984). We also compare our deduced $n(z)$ profiles with direct measurements of $n(z)$ from Devon Island (made at $420 \mathrm{MHz}$ by Robin (1975)). Figure 4 shows the $n(z)$ profiles for the upper $200 \mathrm{~m}$ of these ice masses. These values of $n(z)$ have been used to evaluate the coefficients $\xi_{i}$ and $\zeta_{i}$ by numerical integration, using Table 1 and the definition of $I_{p}$ in Equation (10). The first three terms, in metres, are shown in Table 2.

Substitution of various values of $\theta$ into Equations (11) and (12), using these six coefficients, shows that the refraction correction can be calculated to a precision of better than $1 \mathrm{~m}$ for bedrock angles up to $0.5 \mathrm{rad}\left(29^{\circ}\right)$. It thus seems unnecessary to calculate any of the higherorder terms. For a dry-snow ice mass whose density profile is unkown, an approximate correction for refraction can be made using the average coefficients (20, 11 and $9 \mathrm{~m}$ for the $\xi \mathrm{s}$ and $9,-10$ and $-10 \mathrm{~m}$ for the $\zeta$ s), and Figure 5 shows the size of these approximate corrections. It can be seen from Table 2 that the coefficients are similar for different glaciers, so this approach should not introduce a large error as long as the depth to bubble close-off is within the range $50-70 \mathrm{~m}$. In fact, use of these average values gives errors less than $2 \mathrm{~m}$ for angles up to $0.5 \mathrm{rad}$ when compared against the coefficients given in Table 2 . The numerical integration shows that approximately half of the correction terms $\xi_{1}$ to $\xi_{5}$ and $\zeta_{0}$ to $\zeta_{4}$ are built up in the upper $25 \mathrm{~m}$ of the firn, so that even limited measurements of the density profile will be better than none.

We can also use these average coefficients to estimate the correction for a blue-ice or wet-snow ice mass, since to first order we expect the coefficients to be proportional to the depth of bubble close-off (clearly if this depth is zero, the ice mass is of almost constant refractive index and so the correction terms will be zero).

\section{GENERALIZATION TO THREE DIMENSIONS}

The method we have described can be generalized to allow for the possiblity that the bedrock slope is not parallel to the track followed by the radio-echo sounder. We continue to assume that the refractive index varies only with depth $z$, that the bedrock reflection point is below the depth at which the refractive index becomes constant and that the bedrock surface is planar. Measurements are made on an orthogonal $x-y$ grid of points on the surface.

Table 2. Experimental values (in $m$ ) of the coefficients $\xi_{i}$ and $\zeta_{i}$ for the data sets discussed in the text. The table also shows the estimated value of the depth $z_{\mathrm{f}}$ at which bubble close-off occurs, in $m$

\begin{tabular}{llrrrrrrr} 
Data set & Location & $\xi_{1}$ & $\xi_{3}$ & $\xi_{5}$ & $\zeta_{0}$ & $\zeta_{2}$ & $\zeta_{4}$ & $z_{\mathrm{f}}$ \\
\hline & & & & & & & & \\
& & & & & & & & \\
Langway (1967) & Site 2 & 21.6 & 11.0 & 8.0 & 10.0 & -10.8 & -10.0 & 66 \\
Narita and Maeno (1978) & Mizuho & 17.0 & 8.1 & 5.5 & 8.0 & -8.5 & -7.5 & 52 \\
Nishio (1984) & G2 & 19.1 & 9.2 & 6.3 & 6.4 & -9.5 & -8.5 & 63 \\
Robin (1975) & Devon Island & 22.7 & 13.7 & 11.8 & 10.2 & -11.4 & -12.1 & 62 \\
& & & & & & & &
\end{tabular}




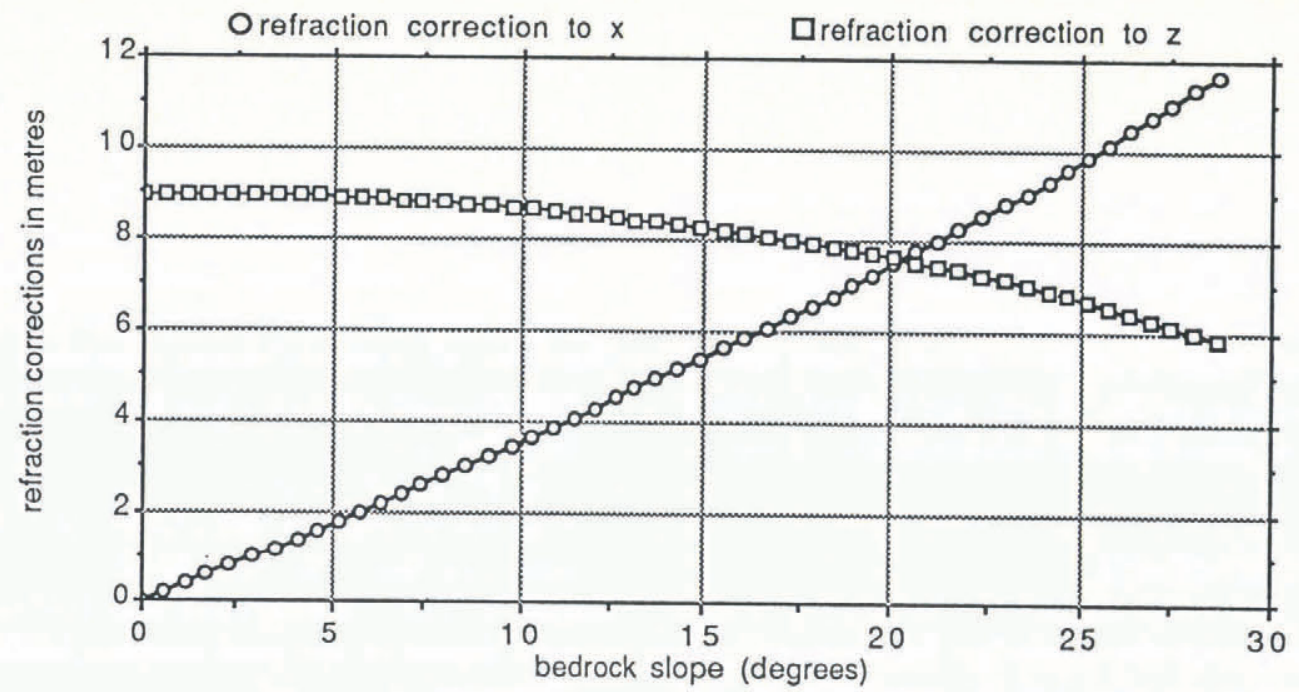

Fig. 5. Typical refraction corrections for an ice sheet whose depth to bubble close-off is about $60 \mathrm{~m}$.

If we write $\mathbf{b}\left(=b_{x}, b_{y}, b_{z}\right)$ for the unit vector normal to the bedrock surface, the equation of the surface is

$$
\mathbf{b} \cdot \mathbf{s}=k
$$

where $k$ is a scalar constant and $\mathbf{s}$ is a vector denoting any point in the surface. Consider a ray which passes through the point $\mathbf{x}$ located at depth $z_{0}$. Since the refractive index is constant below this point, the ray follows a straight path normal to the bedrock, as has already been shown. A point $x_{\mathrm{r}}$ on this ray is thus defined by

$$
\mathbf{x}_{\mathrm{r}}=\mathbf{x}-\alpha \mathbf{b}
$$

where $\alpha$ is the distance from $x$. The ray clearly meets the bedrock surface when

$$
(\mathbf{x}-\alpha \mathbf{b}) \cdot \mathbf{b}=k
$$

so

$$
\alpha=\mathbf{b} \cdot \mathbf{x}-k \text {. }
$$

Thus the total travel time from $x$ to bedrock surface is

$$
T=\frac{n_{\mathrm{i}}}{c}(\mathbf{b} \cdot \mathbf{x}-k) \text {. }
$$

Differentiating this partially with respect to $X$ and $Y$ (the $x$ - and $y$-coordinates of the point $\mathbf{x}$ ) and re-arranging gives

$$
b_{x}=\frac{c}{n_{\mathrm{i}}} \frac{\partial T}{\partial X}
$$

and

$$
b_{y}=\frac{c}{n_{\mathrm{i}}} \frac{\partial T}{\partial Y}
$$

which are the three-dimensional equivalents of Equation (7).

Since $\mathbf{b}$ is a unit vector, $b_{z}^{2}=1-b_{x}^{2}-b_{y}^{2}$ so the inclination $\theta$ of the bedrock to the horizontal is given by

$$
\cos (\theta)=\left(1-b_{x}^{2}-b_{y}^{2}\right)^{\frac{1}{2}}
$$

If this value of $\theta$ is substituted into Equation (12), the $z$ correction will be obtained directly. Substitution into Equation (11) yields the correct magnitude for the horizontal correction, but not its direction. Since the projection of the ray on to a horizontal plane must point in the direction parallel to $\left(b_{x}, b_{y}, 0\right)$, we may write the $x$ and $y$ corrections $x_{\mathrm{r}}^{\prime}$ and $y_{\mathrm{r}}^{\prime}$ as

$$
x_{\mathrm{r}}^{\prime}=\frac{x_{\mathrm{r}} b_{x}}{\left(b_{x}^{2}+b_{y}^{2}\right)^{\frac{1}{2}}}
$$

and

$$
y_{\mathrm{r}}^{\prime}=\frac{x_{\mathrm{r}} b_{\mathrm{y}}}{\left(b_{x}^{2}+b_{y}^{2}\right)^{\frac{1}{2}}}
$$

where $x_{\mathrm{r}}$ is given by Equation (11).

\section{CONGLUSIONS}

We have described a simple method for correcting radioecho-sounding measurements through ice masses for the effects of varying refractive index in the firn layer. This method expresses the corrections to the position of the bedrock reflection point (in the along-track and vertical directions) as polynomials in the bedrock angle $\theta$ (Equations (11) and (12)), and can be generalized to three dimensions. The coefficients of the polynomials can be calculated for a particular ice mass if its refractive index or density profile is known, but examination of measurements of ice masses in Greenland, Antarctica and Devon Island suggests that for dry-snow glaciers the coefficients have fairly well-defined values, and that use of average values is unlikely to introduce errors of more than $3 \%$ of the depth to bubble close-off, i.e. typically $0.03 \times 60 \mathrm{~m}=2 \mathrm{~m}$ for typical dry-snow conditions. The coefficient $\zeta_{0}$ is typical of the magnitude of the corrections (it is the correction which should be applied for an ice mass with a horizontal bedrock surface), and our data show that this coefficient varies between about 6 and $10 \mathrm{~m}$ under these conditions.

This surprisingly good result probably disguises the effects of varying temperature (and crystal orientation) within an ice mass and should perhaps be treated with some caution. However, the validity (and therefore 
usefulness) of the method is not seriously compromised by this uncertainty since what we have developed is essentially a method of locating the position of the bedrock reflection given knowledge of the variation of refractive index with depth. Potentially more serious errors, which the radio-echo-sounding technique is at present unable to address, are caused by non-planarity of the bedrock surface over the scale of the Fresnel zone, and by the fact that there may be a layer of mud or till (between the bottom of the ice and the bedrock) which could give rise to anomalous or indeterminate echoes.

\section{ACKNOWLEDGEMENTS}

We are grateful to $\mathrm{Dr}$ G.deQ. Robin and two anonymous referees for their helpful comments on this paper.

\section{REFERENCES}

Anderson, D. L. and C.S. Benson. 1963. The densification and diagenesis of snow: properties, processes and applications. In Kingery, W. D., ed. Ice and snow. Cambridge, MA, M.I.T. Press, 391-411.

Bogorodskiy, V. V., C. R. Bentley and P. E. Gudmandsen. 1985. Radioglaciology. Dordrecht, Reidel.

Evans, S. 1965. Dielectric properties of ice and snow - a review. 7. Glaciol., 5(42), 773-792.

Fitzgerald, W. J. and J. G. Paren. 1975. The dielectric properties of Antarctic ice. J. Glaciol., 15(73), 39-48.

Goodwin, I. D. 1988. Firn core data from shallow drilling investigations in eastern Wilkes Land, East Antarctica. ANARE Res. Notes 65.

Harrison, C. H. 1970. Reconstruction of subglacial relief for radio echo sounding records. Geophysics, 35, 10991115 .
Jezek, K. 1985. Radar measurements of borehole geometry on the Greenland and Antarctic ice sheets. Geophysics, 50(2), 242-251.

Langway, C. C., Jr. 1967. Stratigraphic analysis of a deep ice core from Greenland. CRREL Res. Rep. 77.

Macqueen, A. D. 1988. Radio echo-sounding as a glaciological technique: a bibliography. Cambridge, Scott Polar Research Institute. World Data Centre 'C' for Glaciology.

Nakawo, M. 1986. Volume expansion of a 413.5-m Mizuho core after its recovery. Mem. Natl. Inst. Polar Res. Spec. Issue, 45, 78-85.

Narita, H. and N. Maeno. 1978. Compiled density data from cores drilled at Mizuho Station. Mem. Natl. Inst. Polar Res. Spec. Issue, 10, 136-158.

Nishio, F. 1984. Stratigraphy and density data from ice core drilled at G2 grid station. JARE Data Rep. 94 (Glaciology 10), 64-83.

Paterson, W.S.B. 1981. The physics of glaciers. Second edition. Oxford, etc., Pergamon.

Rasmussen, L.A. 1986. Refraction correction for radio echo-sounding of ice overlain by firn. J. Glaciol., 32(111), 192-194.

Robin, G.de Q. 1975. Velocity of radio waves in ice by means of a bore-hole interferometric technique. $\mathcal{J}$. Glaciol., 15(73), 151-159.

Salamatin, A. N., V. Ya. Lipenkov, K. Ye. Smirnov and Yu. V. Zhilova. 1985. Plotnost' lednikovogo l'da i yego reologicheskiye svoystva [The density of glacier ice and its rheological properties]. Antarktika. Doklady Komissii, 24, 94-106.

Seligman, G. 1936. Snow structure and ski fields. London, Macmillan.

Yoshino, T. 1961. Radio-wave propagation on the ice cap. Antarct. Rec. (Japan) 11, 228-233.

The accuracy of references in the text and in this list is the responsibility of the authors, to whom queries should be addressed. 